\title{
Predictive Factors for Target Organ Injuries in Hypertensive Individuals
}

\section{Manoel Paz Landim (D) \\ Luciana Neves Cosenso- \\ Martin (D) \\ Aleandra Polegati Santos (C) \\ Jessica Rodrigues Roma \\ Uyemura (iD) \\ Leticia Barufi Fernandes (D) \\ Valquiria da Silva Lopes $(D)$ \\ Juan Carlos Yugar-Toledo (D) \\ Jose Fernando Vilela-Martin (D)}

Internal Medicine Department, State Medical School at Sao Jose do Rio Preto (FAMERP), Sao Jose do Rio Preto, Sao Paulo, Brazil
Correspondence: Jose Fernando Vilela-Martin Internal Medicine Department, State Medical School at Sao Jose do Rio Preto (FAMERP), Ave Brig Faria Lima 54I6, Vila Sao Pedro, Sao Jose do Rio Preto, 15090000, Sao Paulo, Brazil

Email vilelamartin@uol.com.br
Background: The causal relationship between systemic arterial hypertension and target organ damage (TOD) is well known, as well as the association with cardiovascular risk factors (CV). Ambulatory blood pressure monitoring (ABPM) is important in monitoring hypertension and assessing the risk of TOD.

Objective: To evaluate the relationship between blood pressure (BP) and clinical and biochemical parameters in the development of TOD in hypertensive patients.

Methods: This was a retrospective cohort study with 162 hypertensive patients followed for an average period of 13 years. The TOD investigated were left ventricular hypertrophy $(\mathrm{LVH})$, microalbuminuria, coronary artery disease (CAD) and stroke. Blood pressure was assessed by ABPM and $\mathrm{LVH}$ using echocardiogram and electrocardiogram, respectively. Biochemical-metabolic tests and 24-hour microalbuminuria were performed at baseline and follow-up. The P-value $<0.05$ was considered significant.

Results: The average age was $69 \pm 11.8$ years, with a predominance of women $(64.8 \%)$, white ethnicity (79.6\%) and diabetics (78.4\%). ABPM showed a significant reduction in BP values during follow-up, although without association with TOD (microalbuminuria, stroke, and CAD), except for LVH that showed a correlation with sleep BP $\geq 120 / 70 \mathrm{mmHg}(\mathrm{P}=0.044)$. The most frequent TODs were LVH (29.6\%), microalbuminuria (26.5\%), CAD (19.8\%) and stroke (17.3\%). In the follow-up, there was an association between LVH and diabetes; microalbuminuria was associated with diabetes and triglycerides; stroke was associated with HDL-cholesterol (HDL-c), microalbuminuria and carotid disease. CAD showed a relationship with age and HDL-c.

Conclusion: Predictive factors for TOD are age, microalbuminuria, diabetes, HDL-c, triglycerides and carotid disease. Nocturnal BP is correlated with LVH. The absence of a relationship between ABPM and other TODs can be explained by the use of effective drugs, improvement of metabolic and blood pressure parameters.

Keywords: arterial hypertension, ambulatory blood pressure monitoring, left ventricular hypertrophy, albuminuria, stroke, coronary artery disease

\section{Introduction}

The causal relationship between hypertension and target organ damage (TOD) is well known; ${ }^{1}$ however, the numerical value of blood pressure (BP) from which chronic complications in the target organs begin is still discussed. ${ }^{2}$

The concept of prehypertension illustrates the demand for cutoff points in the $\mathrm{BP}$ values from which there is greater or lesser involvement of susceptible organs and to which subpopulation of hypertensive patients the same would apply. ${ }^{3}$ Thus, the appropriate BP values for patients with type 2 diabetes mellitus (DM), the elderly, patients with coronary artery disease (CAD), chronic kidney disease (CKD) and individuals after stroke remain undefined. It remains the subject of research 
regarding the outcomes of acute myocardial infarction (AMI), stroke and cardiovascular death that are directly affected by the most severe stages of hypertension. A study of 4319 individuals showed that cardiovascular outcomes were related to the presence of pre-existing subclinical lesions in isolation or in association, without direct dependence on BP values. ${ }^{4}$ However, most publications evaluated the measure of office BP, sometimes restricted to the systolic component. ${ }^{4}$ SPRINT Trial recently demonstrated a reduction in cardiovascular events associated with more intensive BP control in the office. ${ }^{5}$ On the other hand, the BP obtained by ambulatory blood pressure monitoring (ABPM) has shown greater accuracy of adverse events in relation to office BP, mainly in patients with masked hypertension. In individuals with normal office BP and altered ABPM, there was a higher prevalence of TOD, an unfavorable metabolic profile and a high risk of cardiovascular events compared to patients with normal ABPM. Therefore, ABPM assesses the severity of BP, by analyzing the pressure load on the heart and vessels, predicting cardiovascular risk. ${ }^{6}$

In addition to the BP assessment, the combination of pre-existing TODs increases the risk of developing new injuries by $3.8 \%$ and this information is essential to classify cardiovascular risk, corroborated by the most recent guidelines. ${ }^{7,8}$

The present study evaluated the relationship between BP values obtained by ABPM, metabolic-biochemical parameters and the development of TOD in a population of hypertensive patients followed up in a specialized outpatient clinic.

\section{Method}

\section{Population}

Three hundred and ninety-seven hypertensive patients treated at the specialized hypertension outpatient clinic in the university hospital at State Medical School at Sao Jose Rio Preto were selected in a retrospective cohort study in the period from 2000 to 2016 . The study was approved by the Research Ethics Committee of the institution (CAAE: 20642013.0.0000.5415, no. 427.788 of 10/08/2013).

The inclusion criteria were as follows: two ABPMs, two microalbuminuria measurements in 24-hour urine, serum glucose, creatinine, uric acid and lipid measurements, at different times, at baseline (beginning) and at the end of the follow-up. Secondary hypertension, smokers, estimated glomerular filtration rate $<30 \mathrm{~mL} / \mathrm{min} / \mathrm{m}^{2}$ and individuals with body mass index (BMI) $\geq 35 \mathrm{~kg} / \mathrm{m}^{2}$ were excluded. The smoker individuals were excluded for two main reasons: small group of smokers $<5 \%$ and inconsistent data described about the past and current conditions. After evaluating the inclusion and exclusion criteria, 162 individuals were included.

Participants were assessed for gender, race/ethnicity, age, BMI and follow-up time. Diabetes was defined according to the Brazilian Diabetes Society. ${ }^{9}$ Dyslipidemia was identified by the measurements of total cholesterol (TC), high-density lipoprotein cholesterol (HDL-c) and triglycerides (TG) after a 12-hour fast. The low-density lipoprotein cholesterol (LDL-c) fraction was calculated using the formula LDL-c $=$ TC - HDL-c - TG $/ 5$ (for $\mathrm{TG}<400 \mathrm{mg} / \mathrm{dL}$ ).

The use of statins, fibrates, salicylates and antihypertensive treatment was also evaluated, according to the pharmacological classes: angiotensin-converting enzyme inhibitors (ACEIs) or angiotensin 2 receptor blockers (ARBs), thiazide diuretics, beta-blockers, calcium channel blockers, spironolactone and others, all with regular use for more than one year.

\section{Target Organ Damage}

All TODs were determined at baseline and at the end of the follow-up. TOD patients at some stage in the follow-up period were included. The following injuries were assessed: left ventricular hypertrophy (LVH), microalbuminuria, stroke and CAD.

Left ventricular hypertrophy was defined by means of electrocardiogram (ECG), using Sokolow-Lyon and Cornell voltage criteria, and transthoracic echocardiography (TTE), with determination of left ventricular mass (LVM). ${ }^{7,10,11}$ Increased LVM was considered $>198 \mathrm{~g}$ for women and $>294 \mathrm{~g}$ for men. ${ }^{10,11}$ Microalbuminuria was analyzed in 24-hour urine and was considered abnormal $\geq 30 \mathrm{mg} /$ day.

Individuals with data on the medical records of longterm disability, neurologic dysfunction, cognitive impairment and suspected ischemic and hemorrhagic stroke were submitted to computed tomography or brain magnetic resonance imaging for diagnostic confirmation of cerebral damage. Cerebral micro-bleeding was also included as stroke. Moreover, subjects with diagnostic hypothesis of transitory ischemic attack with normal brain image exams were not included.

All the asymptomatic and symptomatic individuals were submitted to tests to evaluate CAD. Subjects with 
abnormal stress test results, including typical chest pain, were submitted to myocardial scintigraphy or invasive coronary angiography, depending on indication. Significant CAD was defined by invasive coronary angiography as $>50 \%$ stenosis of the left main stem and/or $>70 \%$ stenosis in a major coronary vessel. ${ }^{12,13}$ In cases of MI, the diagnosis was based on clinical history and confirmed by analysis of medical records that showed previous enzymatic alterations (troponin and CK-MB), electrocardiographic alterations suggestive of coronary ischemia and proper treatment for this situation.

Duplex ultrasound was used to identify the carotid stenosis, which was considered present when $>50 \%$ luminal narrowing.

\section{Ambulatory Blood Pressure Monitoring} ABPM was performed with the Spacelabs 90207 device with software for programming the equipment and issuing reports. It was installed during the day and, for 24 hours, it recorded BP measurements every 20 minutes during wakefulness, and every 30 minutes during sleep. Participants were instructed to note daily activities, waking and sleeping times, medications and symptoms, defining periods of wakefulness and sleep. ABPM evaluated systolic (SBP) and diastolic (DBP) blood pressure in 3 periods: 24 hours, wakefulness and sleep. The values of $\mathrm{BP}<130 / 80$ within 24 hours, $<135 / 85$ during wakefulness and $<120 / 70 \mathrm{mmHg}$ during sleep were considered normal. Nocturnal dipper (ND) was standardized as drop $\geq 10 \%$ of SBP in the period of wakefulness to sleep.

\section{Laboratory Tests}

Blood samples were collected after 12 hours of fasting to measure TC, HDL-c, TG, blood glucose, uric acid, serum creatinine and HbA1c. The tests were determined by the electrochemiluminescence method in a COBAS C 501 device with the Roche reagent. The estimated glomerular filtration rate (eGFR) was calculated using the Chronic Kidney Disease Epidemiology Collaboration (CKDEPI ${ }^{14}$ equation and microalbuminuria was measured in 24-hour urine. HbAlc was measured using the highperformance liquid chromatography (HPLC) method, with the Premier HB 9210 device.

\section{Statistical Analysis}

Continuous variables were presented as mean \pm standard deviation and categorical variables as frequency. All clinical, laboratory, ABPM, ECG and echocardiogram parameters were separated into "baseline", when they were the results of the first annotation in the chart and "follow-up", when they represented the last annotation. Student's $t$-test was used to assess the difference between the start and follow-up parameters. Qualitative variables were analyzed using the chi-square or Fisher's exact test. Variables associated with the TOD outcome in the univariate analysis with values of $\mathrm{p}<0.10$ were candidates for the multivariate logistic regression model. The final variables of the model with values of $\mathrm{p}<0.05$ were considered significant. The statistical analysis was performed using the IBMSPSS Statistics for Windows version 21.0 software; IBM Corporation, NY, USA). All tests were two-tailed and $\mathrm{P}$ values $<0.05$ were considered significant.

\section{Results}

The population studied was 162 individuals, with a mean age of $69 \pm 11.8$ years, BMI $=29.27 \mathrm{~kg} / \mathrm{m}^{2}$ and a mean follow-up of $13 \pm 3.13$ years (varying from five to fifteen years). The majority of patients $(67.3 \%)$ were followed-up for more than 10 years.

The majority of the sample was composed of women $(64.8 \%)$ and white ethnicity. The prevalence of DM was 78\%. Thiazide diuretics and ARBs were the most widely used antihypertensive drugs, more than 70\% (Table 1). Table 2 describes the TOD prevalence in the final part of the study. The most prevalent TOD was LVH (on echocardiography, $29.6 \%$ ), followed by microalbuminuria $(26.5 \%)$, CAD (19.8\%), and stroke (17.3\%). In the follow-up, there was a significant reduction in mean SBP and DBP with ABPM and dyslipidemia parameters. There was no difference in office BP values and other laboratory parameters and LVM during follow-up (Table 3). The parameters of glycemic control, eGFR and office BP showed no association with TOD.

The correlation between ABPM parameters and TOD was examined using the Fisher's exact test. The relationship was demonstrated at baseline for LVH (both TTE and $\mathrm{ECG})$ and nocturnal dipper $(\mathrm{P}=0.001$ and $\mathrm{P}=0.016$, respectively), as well as LVH (by ECG) and sleep BP $\geq 120 / 70$ $\mathrm{mmHg}(\mathrm{P}=0.029)$. However, only LVH (by TTE) and sleep $B P \geq 120 / 70 \mathrm{mmHg}$ remained correlated at followup $(\mathrm{P}=0.044)$. All other correlations among the observed parameters of ABPM and TOD were not found.

The variables submitted to univariate logistic regression are shown in Table 4. The mean BP in sleep $\geq 120 / 70$ mmHg (follow-up ABPM) showed a significant relationship with LVH and the 24-hour DBP with CAD. ABPM showed no association with the parameters basal and follow-up of eGFR and microalbuminuria. 
Table I Demographic and General Characteristics at Baseline

\begin{tabular}{|l|l|l|}
\hline Categorical Variables & $\mathbf{N}$ & $\%$ \\
\hline Female & 105 & 64.8 \\
\hline Ethnicity (white) & 129 & 79.6 \\
\hline Diabetes Mellitus & 127 & 78.4 \\
\hline Microalb $\geq 30 \mathrm{mg} / 24 \mathrm{~h}$ & 42 & 25.9 \\
\hline LVM (TTE) (M > 294 g / W $>198 \mathrm{~g})$ & 52 & 32.1 \\
\hline LVH ECG & 35 & 21.6 \\
\hline Betablocker treatment & 78 & 48.1 \\
\hline CCB treatment & 80 & 49.4 \\
\hline ARB treatment & 119 & 73.5 \\
\hline ACE inhibitors treatment & 48 & 29.6 \\
\hline Diuretic treatment & 126 & 77.8 \\
\hline Spironolactone treatment & 16 & 9.9 \\
\hline Aspirin treatment & 78 & 48.1 \\
\hline Statin treatment & 92 & 56.8 \\
\hline Fibrate treatment & 5 & 3.1 \\
\hline Other drugs & 25 & 15.4 \\
\hline Nocturnal Dipping ABPM & 56 & 34.6 \\
\hline
\end{tabular}

Abbreviations: Microalb, microalbuminuria; LVM, left ventricular mass; TTE, transthoracic echocardiography; M, man; W, woman; LVH, left ventricular hypertrophy; ECG, electrocardiogram; CAD, coronary artery disease; $C C B$, calcium channel blocker; ARB, angiotensin 2 receptor blocker; ACEI, angiotensinconverting enzyme inhibitor; ABPM, ambulatory blood pressure monitoring.

Table 2 Target Organ Damage of the Population at Follow-Up

\begin{tabular}{|l|l|l|}
\hline Categorical Variables & N & $\%$ \\
\hline Microalb $\geq 30 \mathrm{mg} / 24 \mathrm{~h}$ & 43 & 26.5 \\
LVM (TTE) (M > $294 \mathrm{~g} / \mathrm{W}>198 \mathrm{~g})$ & 48 & 29.6 \\
LVH ECG & 24 & 14.8 \\
Presence of CAD & 32 & 19.8 \\
Presence of stroke & 28 & 17.3 \\
Presence of carotid artery disease & 43 & 26.5 \\
Nocturnal Dipping ABPM & 47 & 29.0 \\
\hline
\end{tabular}

Abbreviations: Microalb, microalbuminuria; LVM, left ventricular mass; TTE, transthoracic echocardiography; M, man; W, woman; LVH, left ventricular hypertrophy; ECG, electrocardiogram; CAD, coronary artery disease; ABPM, ambulatory blood pressure monitoring.

\section{Left Ventricular Mass}

Upon univariate analysis, LVM (by TTE) showed significance with DM and with sleep BP (ABPM) $\geq 120 / 70$, but in multivariate logistic regression only $\mathrm{DM}$ remained significant $(\mathrm{P}=0.037)$ (Table 5).
Table 3 Laboratory and Left Ventricular Mass (Echocardiogram) Parameters, and Ambulatory Blood Pressure Monitoring Values at Baseline and at Follow-Up

\begin{tabular}{|c|c|c|c|}
\hline \multirow[t]{2}{*}{ Variables } & Basal & Follow-Up & \multirow[t]{2}{*}{$P$-value } \\
\hline & Mean/SD & Mean/SD & \\
\hline TC (mg/dL) & $221.5 \pm 57.7$ & $177.3 \pm 49.8$ & $<0.001$ \\
\hline HDL-c (mg/dL) & $45.9 \pm 13.5$ & $50.7 \pm 13.4$ & $<0.001$ \\
\hline LDL-c (mg/dL) & $139.5 \pm 53.1$ & $96.4 \pm 41.8$ & $<0.001$ \\
\hline TG (mg/dL) & $166.7 \pm 100.2$ & $142.4 \pm 95.6$ & 0.001 \\
\hline eGFR (CKD-EPI) & $65.2 \pm 19.4$ & $65.2 \pm 24.2$ & 0.997 \\
\hline Glucose (mg/dL) & $148 \pm 43.5$ & $137.5 \pm 42.6$ & 0.238 \\
\hline HbAlc (\%) & $7.5 \pm 1.7$ & $7.3 \pm 1.3$ & 0.398 \\
\hline Uric Acid (mg/dL) & $5.9 \pm 1.8$ & $6.0 \pm 1.9$ & 0.164 \\
\hline 24 h Microalb (mg) & $34.4 \pm 60.6$ & $63.0 \pm 211.8$ & 0.664 \\
\hline $\operatorname{LVM}(g)$ & $207.5 \pm 68.3$ & $205.9 \pm 67.4$ & 0.689 \\
\hline OSBP (mmHg) & $|43.9 \pm 2| .8$ & $140.4 \pm 18.2$ & 0.187 \\
\hline ODBP $(\mathrm{mmHg})$ & $87.4 \pm \mid 3.1$ & $85.9 \pm 11.7$ & 0.203 \\
\hline 24 h SBP (mmHg) & $138.5 \pm 16.0$ & $132.9 \pm 14.7$ & $<0.001$ \\
\hline 24 h DBP (mmHg) & $83.3 \pm 12.1$ & $78.1 \pm 10.9$ & $<0.001$ \\
\hline Awake SBP (mmHg) & $140.4 \pm 16.4$ & $134.4 \pm 15.0$ & $<0.001$ \\
\hline Awake DBP (mmHg) & $85.0 \pm 12.4$ & $79.4 \pm 11.6$ & $<0.001$ \\
\hline Sleep SBP (mmHg) & $133.2 \pm 17.5$ & $128.4 \pm 16.5$ & 0.001 \\
\hline Sleep DBP (mmHg) & $78.4 \pm 13.2$ & $73.5 \pm 11.6$ & $<0.001$ \\
\hline
\end{tabular}

Abbreviations: TC, total cholesterol; HDL-c, high density cholesterol; LDL-c, low density cholesterol; TG, triglycerides; eGFR (CKD-EPI), estimated glomerular filtration rate (Chronic Kidney Disease- Epidemiology Collaboration); HbAlc, glycated hemoglobin; Microalb, microalbuminuria; LVM, left ventricle mass; OSBP, office systolic blood pressure; ODBP, office diastolic blood pressure; SBP, systolic blood pressure; DBP, diastolic blood pressure; SD, standard deviation.

\section{Microalbuminuria}

Multivariate logistic regression showed that the predictors of microalbuminuria were the presence of DM and TG (Table 5).

\section{Stroke}

Regarding stroke, the statistical significance of univariate analysis was for male gender, HDL-c, follow-up microalbuminuria $>30 \mathrm{mg} /$ day, carotid disease and LVH by ECG (Table 4). Multivariate analysis showed statistically significant HDL-c, microalbuminuria $>30 \mathrm{mg} /$ day and carotid disease for stroke (Table 5).

\section{Coronary Artery Disease}

The multivariate analysis demonstrated statistical relevance for age and follow-up HDL-c (Table 5).

\section{Discussion}

The present study of hypertensive patients followed for a mean of 13 years \pm 3 years demonstrated that the office $\mathrm{BP}$ values and the ABPM were not directly related to the development of TOD (microalbuminuria, stroke and 
Table 4 Univariate Logistic Regression for Target-Organ Damages at Follow-Up

\begin{tabular}{|c|c|c|c|c|c|c|c|c|c|c|c|c|}
\hline & \multicolumn{3}{|c|}{ LVH } & \multicolumn{3}{|c|}{ Microalb } & \multicolumn{3}{|c|}{ Stroke } & \multicolumn{3}{|c|}{ CAD } \\
\hline & OR & IC & $\mathbf{P}$ & OR & IC & $\mathbf{P}$ & OR & IC & $\mathbf{P}$ & OR & IC & $\mathbf{P}$ \\
\hline AGE & 1.02 & $0.99-1.06$ & 0.108 & 1.00 & $0.97-1.03$ & 0.940 & 1.02 & $0.98-1.05$ & 0.330 & 1.06 & $1.02-1.10$ & 0.003 \\
\hline GENDER (MALE) & 0.51 & $0.24-1.09$ & 0.081 & 1.13 & $0.55-2.33$ & 0.746 & 3.02 & $1.31-6.96$ & 0.009 & 1.85 & $0.84-4.06$ & 0.125 \\
\hline DM & 3.07 & $1.11-8.48$ & 0.03 & 3.43 & $1.13-10.40$ & 0.029 & 1.01 & $0.38-2.73$ & 0.980 & 0.79 & $0.32-1.94$ & 0.603 \\
\hline TC & 1.00 & $0.99-1.01$ & 0.709 & 1.01 & $1.00-1.01$ & 0.078 & 1.00 & $0.99-1.01$ & 0.884 & 1.00 & $0.99-1.00$ & 0.222 \\
\hline TG & 1.00 & $0.99-1.01$ & 0.350 & 1.01 & $1.01-1.05$ & 0.003 & 1.00 & $1.00-1.01$ & 0.234 & 1.0 & $1.00-1.01$ & 0.292 \\
\hline HDL-C & 0.98 & $0.96-1.01$ & 0.238 & 0.98 & $0.95-1.01$ & 0.111 & 0.95 & $0.92-0.99$ & 0.016 & 0.95 & $0.92-0.99$ & 0.009 \\
\hline MICROALB > 30 MG & 1.01 & $0.96-1.04$ & 0.102 & - & - & - & 3.62 & $1.55-8.45$ & 0.003 & 0.58 & $0.22-1.52$ & 0.269 \\
\hline $24 \mathrm{H} \mathrm{DBP}$ & 1.0 & $0.97-1.03$ & 0.998 & 1.02 & $0.99-1.06$ & 0.153 & 1.01 & $0.97-1.05$ & 0.616 & 0.96 & $0.92-1.00$ & 0.049 \\
\hline SLEEP SBP & 1.02 & $1.00-1.04$ & 0.082 & 1.01 & $0.99-1.04$ & 0.200 & 1.00 & $0.98-1.03$ & 0.880 & 1.02 & $0.99-1.04$ & 0.134 \\
\hline SLEEP DBP & 1.03 & $1.00-1.05$ & 0.092 & 1.03 & $1.00-1.06$ & 0.092 & 1.01 & $0.98-1.05$ & 0.434 & 0.98 & $0.94-1.01$ & 0.233 \\
\hline $\mathrm{BP}>\mathrm{I} 20 / 70$ & 3.09 & $1.01-9.43$ & 0.047 & 1.92 & $0.68-5.40$ & 0.216 & 0.76 & $0.28-2.08$ & 0.593 & 1.22 & $0.43-3.5$ & 0.708 \\
\hline LVH (ECG) & - & - & - & 1.02 & $0.98-1.04$ & 0.097 & 2.95 & $1.12-7.80$ & 0.029 & 1.86 & $0.70-4.96$ & 0.215 \\
\hline CAROTID DISEASE & 0.98 & $0.95-1.03$ & 0.104 & 1.03 & $0.99-1.05$ & 0.242 & 3.62 & $1.55-8.45$ & 0.003 & 2.28 & $1.01-5.15$ & 0.047 \\
\hline
\end{tabular}

Note: The significant $\mathrm{P}$-values are marked in bold.

Abbreviations: DM, diabetes mellitus; TC, total cholesterol; TG, triglycerides; HDL-c, high-density cholesterol; Microalb, microalbuminuria; SBP, systolic blood pressure; DBP, diastolic blood pressure; BP, blood pressure; LVH (ECG), left ventricular hypertrophy by electrocardiogram; LVH, left ventricular hypertrophy (assessed by left ventricular mass); CAD, coronary artery disease; $\mathrm{OR}$, odds ratio; $\mathrm{Cl}$, confidence interval; $\mathrm{P}$, P-value.

Table 5 Multivariate Logistic Regression for Target-Organ Damages at Follow-Up

\begin{tabular}{|l|l|l|l|l|l|l|l|l|l|l|l|l|l|}
\hline \multirow{2}{*}{} & \multicolumn{3}{|c|}{ LVH } & \multicolumn{3}{c|}{ Microalb } & \multicolumn{3}{c|}{ Stroke } & \multicolumn{3}{c|}{ CAD } \\
\cline { 2 - 13 } & OR & \multicolumn{1}{|c|}{ IC } & P & OR & \multicolumn{1}{|c|}{ IC } & P & OR & IC & P & OR & IC & P \\
\hline AGE & - & - & - & - & - & - & - & - & & - & 1.07 & $1.03-1.11$ & $\mathbf{0 . 0 0 2}$ \\
DM & 3.0 & $1.07-8.39$ & $\mathbf{0 . 0 3 7}$ & 5.17 & $1.51-17.74$ & $\mathbf{0 . 0 0 9}$ & - & - & & - & - & - & - \\
TG & - & - & - & 1.01 & $1.00-1.05$ & $\mathbf{0 . 0 1}$ & - & - & - & - & - & - \\
HDL-C & - & - & - & - & - & - & 0.95 & $0.90-0.99$ & $\mathbf{0 . 0 2 7}$ & 0.95 & $0.91-0.98$ & $\mathbf{0 . 0 0 4}$ \\
MICROALB & - & - & - & - & - & - & 4.27 & $1.50-12.17$ & $\mathbf{0 . 0 0 7}$ & - & - & - \\
CAROTID DISEASE & - & - & - & - & - & - & 3.12 & $1.09-8.90$ & $\mathbf{0 . 0 3 4}$ & - & - \\
\hline
\end{tabular}

Note: The significant $P$-values are marked in bold.

Abbreviations: DM, diabetes mellitus; TG, triglycerides; HDL-c, high density cholesterol; Microalb, microalbuminuria; LVH, left ventricular hypertrophy (assessed by left ventricular mass); CAD, coronary artery disease; $\mathrm{OR}$, odds ratio; $\mathrm{Cl}$, confidence interval; $\mathrm{P}, \mathrm{P}$-value.

CAD), considering the normal behavior of the BP during wakefulness and the close to adequate control in the 24 $h$ (ABPM), a fact that reduced the association of hypertension with these evaluated organic lesions. Hypertension is involved in more than $50 \%$ of deaths caused by CVD, ${ }^{15,16}$ being a risk factor with a greater impact for stroke compared to CAD. Thus, BP control is critical to prevent TODs induced by hypertension, according to a metaanalysis that compared intensive BP control versus standard. ${ }^{17}$ In addition to BP control, the high percentage of treatment with target organ protective antihypertensive drugs (thiazides and blockers of the renin-angiotensinaldosterone system) may also have contributed to this finding. ${ }^{18-20}$ Additionally, the follow-up showed improvement in dyslipidemia; however, diabetes control has not changed. Therefore, the results showed the importance of other risk factors for the development of TOD, other than just BP. Renal function, glycemia, and microalbuminuria remained stable during follow-up, demonstrating that adequate BP control may have influenced these subclinical TODs in the long term.

According to Clement et al, who evaluated the association between ABPM and subsequent cardiovascular events in 1963 treated hypertensive patients followed for 5 years, a mean 24-hour SBP lower than $135 \mathrm{mmHg}$ decreased cardiovascular risk even after adjustment for office BP and other confounders. ${ }^{21}$ In our study, the mean 24-hour SBP of follow-up was $132.9 \mathrm{mmHg}$, a fact that may explain the TOD protection found in cases of microalbuminuria, stroke and CAD. However, the only ABPM 
parameter correlated to TOD in the follow-up, in this case LVH, was sleep BP $\geq 120 / 70 \mathrm{mmHg}$. Therefore, our results demonstrated that ABPM correlates to $\mathrm{LVH}$, similar to study performed by Bliziotis et al, who showed relationship more important between ABPM and LV geometry than office $\mathrm{BP}^{22}$

The most frequent TOD in our study was LVH (observed by LVM), similar to a study that showed LVH prevalence ranging from $36 \%$ to $41 \%{ }^{23}$ Considering that almost $80 \%$ of our sample had DM, a higher prevalence could be expected of LVH, since Cuspidi et al demonstrated a higher prevalence of LVH ( $58 \%$ to $77 \%$ ) in conditions, such as severe hypertension, DM or cardiovascular disease. ${ }^{24}$ On the other hand, Wang et al found a $23 \%$ prevalence of LVH in asymptomatic diabetics over 65 years of age, similar to our study. ${ }^{25}$ In any case, the use of drugs that act on ventricular remodeling and the reduction in BP observed by ABPM may explain the lower prevalence of LVH in our sample. ${ }^{18,26}$ However, the LVM calculation method without body surface correction may have interfered with our results. According to Yildiz et al, the two-dimensional echocardiogram is the most used in the evaluation of the LV (left ventricular) geometry and the relative thickness of the LV wall; however, it is less accurate in asymmetric hypertrophy. ${ }^{23}$ Our patients had hypertension with concentric hypertrophy, which is expected in this morbidity. Thus, as it is difficult to establish standards for assessing LVM, correcting for body surface or height, especially in extreme obesity, ${ }^{23}$ we consider that the exclusion of moderate to severe obesity in our series reduced the probable interference of obesity in LVM calculation.

Although the two outcomes assessed, LVH and CAD, showed a significant relationship with ABPM on univariate analysis, they did not remain on multivariate. As discussed previously, the Fisher's correlation showed an association between LVH and sleep BP $\geq 120 / 70 \mathrm{mmHg}$, a situation observed by other authors, who described that LVM correlated with the nocturnal systolic component of $\mathrm{BP}^{27}$ and with no difference in BP between waking and sleeping periods. ${ }^{6,28,29}$ Similarly, the SPRINT study demonstrated that intensive control of systolic BP (SBP $<120 \mathrm{mmHg}$ ) decreased the risk of developing LVH and caused LVH regression in individuals with this pre-existing change. ${ }^{30}$

In the present study, DM was an independent predictor of $\mathrm{LVH}$, a fact that was also observed in prediabetic patients by other authors. ${ }^{31,32}$ The LVH assessment, using ECG, was related to stroke, even though multivariate analysis was not significant. Corroborating this finding, the ALLHAT study reported an association between LVH (by ECG) and increased cardiovascular risk and all-cause mortality in treated hypertensive patients. ${ }^{33}$ More recently, Cao et al showed that each 19 $\mathrm{mmHg}$ increase in SBP led to a $49 \%$ higher risk of $\mathrm{LVH}$, emphasizing the importance of ECG as a predictor of LVH. ${ }^{34}$ Regarding microalbuminuria, DM and TG were predictors of this subclinical lesion, compatible with studies in diabetics ${ }^{35}$ and non-diabetics. ${ }^{36}$ Additionally, TG can be a predictor of decline in renal function. ${ }^{37,38}$ In our study, better glycemic control $(\mathrm{HbAlc}=7.3 \%)$ had no influence on the presence of microalbuminuria, since this correlation has been found with higher $\mathrm{HbAlc}$ values $(>10.5 \%){ }^{39}$

Our results demonstrated that HDL-c, microalbuminuria $\geq 30 \mathrm{mg}$ and the presence of carotid disease were associated with the development of stroke. The protective association of HDL-c for stroke has also been previously demonstrated for ischemic and hemorrhagic stroke. ${ }^{40,41}$ Most diabetics in our sample reaffirm the impact of DM as a risk factor for stroke, since albuminuria in diabetics increased the risk of stroke in about $80 \%{ }^{42}$ On the other hand, the SPRINT trial found an association between microalbuminuria and stroke in the absence of $\mathrm{DM}^{43}$ Our study did not show an association between glycemia and stroke, as HbAlc was close to normal, unlike the higher risk of stroke observed with $\mathrm{HbAlc}>10 \%{ }^{42}$ Finally, the presence of CVD, including peripheral arterial disease, CAD and carotid disease, represents a wellestablished risk factor for stroke. ${ }^{44,45}$

Regarding $\mathrm{CAD}$, there was no association with 24-hour DBP, a finding similar to two American studies, NHANES (National Health and Nutrition Examination Survey/20132016) and ARIC (Atherosclerosis Risk in Communities Study). ${ }^{46}$ We also observed that only age and HDL-c were predictors of $\mathrm{CAD}$, which is consistent with large observational studies. ${ }^{47,48}$ In our data, we observed that the average HDL-c of around $50 \mathrm{mg} / \mathrm{dL}$ led to a reduction in relative risk by about $5 \%$. Recently, a cardiovascular risk survey of the Brazilian adult population showed that age and HDL-c were indicators of CV risk. ${ }^{49}$

\section{Study Limitations and Strengths}

Some limitations deserve to be mentioned. Initially, it was a retrospective observational cohort study with analysis of medical records, which could change the accuracy of the 
data, although the inclusion and exclusion criteria tried to reduce this effect. Secondly, we did not use LV mass index calculation to assess LVH, but only LVM. However, we consider that the exclusion of obese patients with grades 2 and 3 reduced possible interferences. Third, smoking was not assessed as a risk factor due to inconsistent medical record data. Fourth, CAD was considered only in patients undergoing hemodynamic evaluation, not including individuals with possible coronary lesions, without imaging exams. Finally, the sample number may have influenced variables that are generally associated with TODs.

As this is a real-life study, of a cohort of hypertensive individuals with established TOD, this research highlights the impact of risk factors and complications generated by hypertension throughout the natural history of the disease. The exclusion of smokers and moderate to severe obesity reduced the confounding factors in the data analysis. Finally, the lack of correlation between TOD and BP values (observed by ABPM), except for nocturnal BP, which correlated with $\mathrm{LVH}$, reaffirms the importance of controlling other risk factors with measures that act in the progression of atherosclerotic disease.

\section{Conclusion}

In a population of hypertensive patients, mostly diabetic, followed for about 13 years, LVH was the most prevalent TOD, followed by microalbuminuria, CAD and stroke. LVH was associated with DM and microalbuminuria. Microalbuminuria was a predictive factor for stroke and HDL-c showed an inverse relationship with stroke and CAD. There was no association of ABPM parameters with microalbuminuria, stroke, and CAD. However, sleep BP on the ABPM was correlated with LVH. Satisfactory BP control, use of effective drugs in reducing CV risk and improvement of other metabolic parameters during follow-up were protective factors in this cohort of hypertensive patients.

\section{Consent Statement}

Approval was obtained from the Research Ethics Committee of the State Medical School at Sao Jose do Rio Preto (FAMERP) according to national and international guidelines. The consent to review the medical records was not required by the ethics committee of the institution, because the committee waives it in cases of the retrospective nature of the research. The authors declare that this research complies with the privacy of the participants, with the data maintained anonymous and confidential. The current study was performed according to the ethical standards of the Helsinki Declaration.

\section{Academic Link}

This study is part of the Master's thesis by Landim MP.

\section{Acknowledgments}

The authors wish to thank the reviewer for correcting both spelling and grammar of the English text.

\section{Funding}

The present study had no external funding sources.

\section{Disclosure}

The authors report no conflicts of interest in this work.

\section{References}

1. Cameron AC, Lang NN, Touyz RM. Drug treatment of hypertension: focus on vascular health. Drugs. 2016;76(16):1529-1550. doi:10.1007/s40265-016-0642-8

2. Williamson JD, Supiano MA, Applegate WB, et al. Intensive vs standard blood pressure control and cardiovascular disease outcomes in adults aged $\geq 75$ years: a randomized clinical trial. JAMA. 2016;315 (24):2673-2682. doi:10.1001/jama.2016.7050

3. Malachias MVB, Gomes MAM, Nobre F, Alessi A, Feitosa AD, Coelho EB. 7th Brazilian guideline on hypertension. Arq Bras Cardiol. 2016;107(3Supl.3):7-13. doi:10.5935/abc.20160152

4. Vernooij JW, van der Graaf Y, Nathoe HM, Bemelmans RH, Visseren FL, Spiering W. Hypertensive target organ damage and the risk for vascular and all-cause mortality in patients with vascular disease. $J$ Hypertens. 2013;31(3):492-499. doi:10.1097/HJH.0b013e32835cd3cd

5. Wright JT, Williamson JD, Whelton PK, et al.; The SPRINT Research Group. A randomized trial of intensive versus standard blood-pressure control. N Engl J Med. 2015;373(22):2103-2116. doi:10.1056/NEJMoa1511939.

6. Mancia G, Verdecchia P, Boehme AK, Esenwa C. Clinical value of ambulatory blood pressure: evidence and limits. Circ Res. 2015;116 (6):1034-1045. doi:10.1161/CIRCRESAHA.116.303755

7. Williams B, Mancia G, Spiering W, et al. 2018 ESC/ESH guidelines for the management of arterial hypertension - the task force for the management of arterial hypertension of the European Society of Cardiology (ESC) and the European Society of Hypertension (ESH). Eur Heart J. 2018;39(33):3021-3104. doi:10.1093/eurheartj/ehy339

8. Sebba Barroso WK, Rodrigues CIS, Bortolotto LA, et al. Brazilian Guidelines of Hypertension - 2020. Arq Bras Cardiol. 2021;116 (3):516-658. doi:10.36660/abc.20201238

9. Brazilian Diabetes Society Guidelines: 2019-2020 [homepage on the Internet]. Available from: https://www.diabetes.org.br/profissional/ images/DIRETRIZES-COMPLETA-2019-2020.pdf. Accessed April 05, 2021.

10. Barbosa MM, Nunes MCP, Campos Filho O, et al. Brazilian Society of Cardiology. Guidelines for echocardiography indications. Arq Bras Cardiol. 2009;93(6suppl.3):e265-e302.

11. Lang RM, Badano LP, Mor-Avi V, et al. Recommendations for cardiac chamber quantification by echocardiography in adults: an update from the American Society of Echocardiography and the European Association of Cardiovascular Imaging. $\mathrm{J} \mathrm{Am} \mathrm{Soc}$ Echocardiogr. 2015;28(1):1-39.e14. doi:10.1016/j.echo.2014.10.003 
12. Rosenthal RL. The 50\% coronary stenosis. Am J Cardiol. 2015;115 (8):1162-1165. doi:10.1016/j.amjcard.2015.01.553

13. Neglia D, Rovai D, Caselli C, et al.; EVINCI Study Investigators. Detection of significant coronary artery disease by noninvasive anatomical and functional imaging. Circ Cardiovasc Imaging. 2015;8(3): e002179. doi:10.1161/CIRCIMAGING.114.002179.

14. Levey AS, Stevens LA, Schmid CH, et al.; CKD-EPI (Chronic Kidney Disease Epidemiology Collaboration). A new equation to estimate glomerular filtration rate. Ann Intern Med. 2009;150 (9):604-612. doi:10.7326/0003-4819-150-9-200905050-00006.

15. Bronner LL, Kanter DS, Manson JE. Primary prevention of stroke. N Engl J Med. 1995;333(21):1392-1400. doi:10.1056/NEJM199511 233332106

16. He J, Whelton PK. Elevated systolic blood pressure and risk of cardiovascular and renal disease: overview of evidence from observational epidemiologic studies and randomized controlled trials. Am Heart J. 1999;138(3):211-219. doi:10.1016/s0002-8703(99)70312-1

17. Xie X, Atkins E, Lv J, et al. Effects of intensive blood pressure lowering on cardiovascular and renal outcomes: updated systematic review and meta-analysis. Lancet. 2016;387(10017):435-443. doi:10.1016/S0140-6736(15)00805-3

18. Yusuf S, Teo KK, Pogue J, et al.; The ONTARGET Investigators. Telmisartan, ramipril, or both in patients at high risk for vascular events. $N$ Engl J Med. 2008;358(15):1547-1559. doi:10.1056/ NEJMoa0801317.

19. Curb JD, Pressel SL, Cutler JA, et al. Effect of diuretic-based antihypertensive treatment on cardiovascular disease risk in older diabetic patients with isolated systolic hypertension: systolic hypertension in the Elderly Program Cooperative Research Group. JAMA. 1996;276 (23):1886-1892. doi:10.1001/jama.1996.03540230036032

20. ALLHAT Officers and Coordinators for the ALLHAT Collaborative Research Group. The antihypertensive and lipid-lowering treatment to prevent heart attack trial. Major outcomes in high-risk hypertensive patients randomized to angiotensin-converting enzyme inhibitor or calcium channel blocker vs diuretic: the Antihypertensive and Lipid-Lowering Treatment to Prevent Heart Attack Trial (ALLHAT). JAMA. 2002;288(23):2981-2997. doi:10.1001/ jama.288.23.2981.

21. Clement DL, Buyzere ML, Bacquer DA, et al.; Office versus Ambulatory Pressure Study Investigators. Prognostic value of ambulatory blood-pressure recordings in patients with treated hypertension. N Engl J Med. 2003;348:2407-2415. doi:10.1056/ NEJMoa022273

22. Bliziotis IA, Destounis A, Stergiou GS. Home versus ambulatory and office blood pressure in predicting target organ damage in hypertension: a systematic review and meta-analysis. J Hypertens. 2012;30 (7):1289-1299. doi:10.1097/HJH.0b013e3283531eaf

23. Yildiz M, Oktay AA, Stewart MH, Milani RV, Ventura HO, Lavie CJ. Left ventricular hypertrophy and hypertension. Prog Cardiovasc Dis. 2020;63(1):10-21. doi:10.1016/j.pcad.2019.11.009

24. Cuspidi C, Sala C, Negri F, Mancia G, Morganti A. Italian Society of Hypertension. Prevalence of left-ventricular hypertrophy in hypertension: an updated review of echocardiographic studies. J Hum Hypertens. 2012;26(6):343-349. doi:10.1038/jhh.2011.104

25. Wang Y, Yang H, Huynh Q, et al. Diagnosis of nonischemic stage B heart failure in type 2 diabetes mellitus: optimal parameters for prediction of heart failure. JACC Cardiovasc Imaging. 2018;11 (10):1390-1400. doi:10.1016/j.jcmg.2018.03.015

26. Brunström M, Carlberg B. Association of blood pressure lowering with mortality and cardiovascular disease across blood pressure levels: a systematic review and meta-analysis. JAMA Intern Med. 2018;178(1):28-36. doi:10.1001/jamainternmed.2017.6015

27. Guang H, Wang X, Treiber F, Harshfield G, Kapuku G, Su S. Blood pressure trajectories, carotid artery intima-media thickness and left ventricular mass: results from a 23-year longitudinal study from childhood to young adulthood. Circulation. 2016;134:A18729.
28. Verdecchia P, Schillaci G, Guerrieri M, et al. Circadian blood pressure changes and left ventricular hypertrophy in essential hypertension. Circulation. 1990;81:528-536. doi:10.1161/01.CIR.81.2.528

29. Palatini P, Penzo M, Racioppa A, et al. Clinical relevance of nighttime blood pressure and of daytime blood pressure variability. Arch Intern Med. 1992;152:1855-1860. doi:10.1001/archinte.1992.00 400210081013

30. Soliman EZ, Ambrosius WT, Cushman WC, et al.; SPRINT Research Study Group. Effect of intensive blood pressure lowering on left ventricular hypertrophy in patients with hypertension: SPRINT (Systolic Blood Pressure Intervention Trial). Circulation. 2017;136 (5):440-450. doi:10.1161/CIRCULATIONAHA.117.028441.

31. Skali H, Shah A, Gupta DK, et al. Cardiac structure and function across the glycemic spectrum in elderly men and women free of prevalent heart disease: the atherosclerosis risk in the community study. Circ Heart Fail. 2015;8(3):448-454. doi:10.1161/ CIRCHEARTFAILURE.114.001990

32. Iwakura K. Heart failure in patients with type 2 diabetes mellitus: assessment with echocardiography and effects of antihyperglycemic treatments. $J$ Echocardiogr. 2019;17(4):177-186. doi:10.1007/ s12574-019-00446-9

33. Bang CN, Soliman EZ, Simpson LM, et al.; ALLHAT Collaborative Research Group. Electrocardiographic left ventricular hypertrophy predicts cardiovascular morbidity and mortality in hypertensive patients: the ALLHAT study. Am J Hypertens. 2017;30(9):914-922. doi:10.1093/ajh/hpx067.

34. Cao X, Broughton ST, Waits GS, Nguyen T, Li Y, Soliman EZ. Interrelations between hypertension and electrocardiographic left ventricular hypertrophy and their associations with cardiovascular mortality. Am J Cardiol. 2019;123(2):274-283. doi:10.1016/j. amjcard.2018.10.006

35. Bardini G, Innocenti M, Rotella CM, Giannini S, Mannucci E. Variability of triglyceride levels and incidence of microalbuminuria in type 2 diabetes. J Clin Lipidol. 2016;10(1):109-115. doi:10.1016/j. jacl.2015.10.001

36. Xie Q, Xu C, Wan Q. Association between microalbuminuria and outcome of non-diabetic population aged 40 years and over: the reaction study. Prim Diabetes Care. 2020;14(4):376-380. doi:10.1016/j.pcd.2019.12.003

37. Cao Y, Sun G, Liu R, et al. Plasma triglyceride levels and central obesity predict the development of kidney injury in Chinese community older adults. Ren Fail. 2019;41(1):946-953. doi:10.1080/ 0886022X.2019.1655451

38. Huang F, Wang L, Zhang Q, et al. Elevated atherogenic index and higher triglyceride increase risk of kidney function decline: a 7-year cohort study in Chinese adults. Ren Fail. 2021;43(1):32-39. doi:10.1080/0886022X.2020.1853569

39. Showail AA, Ghoraba M. The association between glycemic control and microalbuminuria in type 2 diabetes. Saudi J Kidney Transpl. 2016;27(3):473-479. doi:10.4103/1319-2442.182379

40. Shen Y, Shi L, Nauman E, et al. Inverse association between HDL (High-Density Lipoprotein) cholesterol and stroke risk among patients with type 2 diabetes mellitus. Stroke. 2019;50(2):291-297. doi:10.1161/STROKEAHA.118.023682

41. Watanabe J, Kakehi E, Kotani K, Kayaba K, Nakamura Y, Ishikawa S. Isolated low levels of high-density lipoprotein cholesterol and stroke incidence: JMS Cohort Study. J Clin Lab Anal. 2020;34:e23087. doi:10.1002/jcla.23087

42. Hitman GA, Colhoun H, Newman C, et al.; CARDS Investigators. Stroke prediction and stroke prevention with atorvastatin in the Collaborative Atorvastatin Diabetes Study (CARDS). Diabet Med. 24;2007;1313-1321. doi:10.1111/j.1464-5491.2007.02268.x

43. Leitão L, Soares-dos-Reis R, Neves JS, Baptista RB, Vieira MB, Causland FR. Intensive blood pressure treatment reduced stroke risk in patients with albuminuria in the SPRINT trial. Stroke. 2019;50:3639-3642. doi:10.1161/STROKEAHA.119.026316 
44. Kernan WN, Ovbiagele B, Black HR, et al. Guidelines for the prevention of stroke in patients with stroke and transient ischemic attack: a guideline for healthcare professionals from the American Heart Association/American Stroke Association. Stroke. 2014;45(7):2160-2236. doi:10.1161/STR.00000000 00000024

45. Boehme AK, Esenwa C, Elkind MSV. Stroke risk factors, genetics, and prevention. Circ Res. 2017;120:472-495. doi:10.1161/ CIRCRESAHA.116.308398

46. McEvoy JW, Daya N, Rahman F, et al. Association of isolated diastolic hypertension as defined by the 2017 ACC/AHA blood pressure guideline with incident cardiovascular outcomes. JAMA. 2020;323(4):329-338. doi:10.1001/jama.2019.21402
47. Assmann G, Cullen P, Schulte H. Simple scoring scheme for calculating the risk of acute coronary events based on the 10year follow-up of the cardiovascular prospective Münster (PROCAM) study. Circulation. 2002;105(3):310-315. doi:10.1161/hc0302.102575

48. D'Agostino RB, Vasan RS, Pencina MJ, et al. General cardiovascular risk profile for use in primary care: the Framingham Heart Study. Circulation. 2008;117(6):743-753. doi:10.1161/CIRCULATIONA HA.107.699579

49. Malta DC, Pinheiro PC, Teixeira RA, Machado IE, Santos FM, Ribeiro ALP. Estimates of ten-year cardiovascular risk in the Brazilian population: a population-based study. Arq Bras Cardiol. 2021;116(3):423-431. doi:10.36660/abc.20190861

\section{Publish your work in this journal}

Integrated Blood Pressure Control is an international, peer-reviewed open-access journal focusing on the integrated approach to managing hypertension and risk reduction. Treating the patient and comorbidities together with diet and lifestyle modification and optimizing healthcare resources through a multidisciplinary team approach constitute key features of the journal. This journal is indexed on
American Chemical Society's Chemical Abstracts Service (CAS). The manuscript management system is completely online and includes a very quick and fair peer-review system, which is all easy to use. Visit http://www.dovepress.com/testimonials.php to read real quotes from published authors. 